\title{
Use of Clozapine for Borderline Personality Disorder: A Case Report
}

\author{
Badii Amamou, Walid Bel Hadj Salah, Ahmed Mhalla, Nejla Benzarti, Hend Elloumi, Ferid Zaafrane, Lotfi Gaha \\ Department of Psychiatry, Fattouma Bourguiba Hospital, Monastir, Tunisia
}

\begin{abstract}
Patients with borderline personality disorder (BPD) show significant impairment in functioning, particularly in the interpersonal and social domains. Prior reports suggest that clozapine may be effective in the management of BPD. We present the case of a patient with BPD who experienced persistent suicidal ideation and was treated with clozapine at a state psychiatric hospital. After treatment failure with other psychotropic medications, clozapine medication was initiated; not only did suicidal ideation cease, but social and professional functioning also greatly improved to the point of no longer requiring intensive levels of observation or restrictive procedures. Clozapine appears to be efficacious in the management of suicide attempts and self-injurious behavior. Moreover, it appears to be promising as a therapeutic measure for ameliorating the global functioning of patients with severe BPD. Larger, randomized, blinded, and controlled prospective studies are needed to confirm these findings and to determine optimal dosage.
\end{abstract}

KEY WORDS: Borderline personality disorder; Suicide; Social adjustment; Clozapine.

\section{INTRODUCTION}

Patients with borderline personality disorder (BPD) show significant impairment in the domain of interpersonal and social functioning and may be heavy users of health and social services resources, albeit with little beneficial outcome. BPD affects approximately $1 \%$ to $2 \%$ of the general population and up to $20 \%$ of psychiatric patients. ${ }^{1)}$

BPD is a serious mental disorder that is difficult to treat; although BPD has been the focus of more medication trials than any other Axis II disorder, there are presently no clear guidelines in the literature regarding the use of pharmacotherapy in its management.

Clozapine is among the medications that have been evaluated for the treatment of severe BPD. Based on the scanty literature available in the form of case reports and small studies, there is some evidence that it is effective in the management of BPD. ${ }^{2-4)}$

The present study aims to describe the effectiveness of clozapine in a patient with severe BPD without psychotic

\footnotetext{
Received: June 1, 2015 / Revised: September 17, 2015

Accepted: December 1, 2015

Address for correspondence: Badii Amamou, MD

Department of Psychiatry, Fattouma Bourguiba Hospital, Avenue

Farhat HACHED 5000, Monastir. Tunisia

Tel: +216-73461141, Fax: +216-98475488

E-mail: amamoubadii@hotmail.fr
}

features who had severe recurrent suicidal thoughts, repeated and prolonged periods of hospitalization, and was unsuccessfully treated with other psychotropic medications.

We used the Social Functioning Scale (Markers version) to assess the patient's social functioning ${ }^{5}$; this scale is a generic questionnaire that measures social and professional functioning along six major dimensions (social withdrawal, relationships, recreational activities, independence [competence], independence [performance], and employment).

\section{CASE}

A male patient, 33 years of age and the youngest among five siblings, was born after a normal and accepted, though unplanned, pregnancy. His psychomotor development was normal, but during adolescence and early adulthood he exhibited instability in intimate relationships and in the professional sphere.

He had a brother 17 years his senior who, despite no known psychiatric history, died by hanging himself when the patient was five years old. The patient assisted at the scene, and later recounted that the memory of the event stayed with him as a recurring image.

He also has two sisters, both of whom are being regularly followed in our ward for recurrent depressive dis-

(c) This is an Open-Access article distributed under the terms of the Creative Commons Attribution Non-Commercial License (http://creativecommons.org/licenses/by-nc/4.0) which permits unrestricted non-commercial use, distribution, and reproduction in any medium, provided the original work is properly cited. 
order, but who have never been hospitalized. One of the sisters relapsed mildly in March 2015 after cessation of anti-depressive medication.

The patient's mother is regarded by our team of doctors as chronically depressed.

The patient has been followed for two years for major depressive disorder and BPD. He has attempted suicide three times. The first attempt involved electrocution in February 2013, and represented an impulsive and nonpremeditated act without specific triggering factors, whereas the second and third attempts involved ingesting chloralose, a chemical used to exterminate rats.

He has been hospitalized twice as a consequence of these suicide attempts (one suicide attempt occurred while he was already admitted to the hospital; he was stopped by a team of nurses who noticed the chemical in his possession upon his return from an authorized visit to his father, who had recently suffered a stroke that rendered him quadriplegic). His last hospital admission was in August 2014, at which time he was clearly distressed and challenging in his behavior, exhibiting a lack of cooperation and an inability to express anything but a desire to be free either of his suicidal thoughts or of his life. He displayed no remorse following his intake of chloralose and expressed pessimism concerning the possibility of being helped, asserting that he still considered suicide to be the perfect solution in the absence of a medication that could eliminate his persistent thoughts of self-harm.

He displayed the same set of symptoms during each hospitalization period; impulsivity, irritability, sadness, and intrusive ideas of self-harm. In addition, he exhibited very poor social and professional functioning, with his

Table 1. Psychometric scales with the increase of clozpine dose

\begin{tabular}{lccccc}
\hline \multicolumn{1}{c}{ Date } & HDS & BPRS & $\begin{array}{c}\text { Barratt scale } \\
\text { of impulsivity }\end{array}$ & $\begin{array}{c}\text { Sofa } \\
\text { (\%) }\end{array}$ & $\begin{array}{c}\text { Clozapine } \\
\text { dose (mg) }\end{array}$ \\
\hline October 20, 2014 & 21 & 47 & 87 & 30 & 25 \\
October 27, 2014 & 21 & 49 & 87 & 60 & 50 \\
November 3, 2014 & 17 & 45 & 83 & 60 & 75 \\
November 10, 2014 & 14 & 27 & 79 & 64 & 100 \\
November 17, 2014 & 08 & 22 & 74 & 72 & 125 \\
November 24, 2014 & 03 & 20 & 70 & 80 & 150 \\
December 1, 2014 & 01 & 20 & 64 & 90 & 175 \\
December 8, 2014 & 03 & 20 & 62 & 95 & 200 \\
December 15, 2014 & 03 & 20 & 57 & 95 & 225 \\
December 23, 2014 & 01 & 23 & 51 & 95 & 250 \\
December 30, 2014 & 02 & 20 & 45 & 97 & 275 \\
January 6, 2015 & 01 & 20 & 45 & 97 & 300 \\
April 1, 2015 & 0 & 20 & 41 & 100 & 300 \\
\hline
\end{tabular}

HDS, Hamilton Depression Scale; BPRS, Brief Psychiatric Rating Scale; Sofa, Social Functioning Scale (Markers version). scores on the Social Functioning Scale (Markers version) consistently falling below $30 \%$.

He has received a variety of anti-depressive treatments including clomipramine, escitalopram, sertraline, paroxetine, venlafaxine and mood stabilizers (lithium, lamotrigine, olanzapine, risperidone and amisulpride). The dosage used was adequate and the period of treatment for each of these drugs was never shorter than eight weeks. Ultimately, only paroxetine offered some tangible, although partial, benefit: his score on the Hamilton Depression Scale dropped by six points from 25 to 19 points, but it remains unclear if the observed effect was partly due to the psychotherapy he had been undergoing for a period of three months prior to receiving paroxetine.

Given these unsatisfactory treatment results, the patient's poor global functioning and the pressing risk of suicide, treatment with clozapine was initiated once the consent of the patient and the ethical committee of the hospital were obtained.

The patient responded to a dose of $300 \mathrm{mg}$ per day (he continued to experience intrusive suicidal ideation at doses of 250 and $275 \mathrm{mg}$ ), with a bloodstream level of $392.8 \mathrm{ng} / \mathrm{ml}$, along with paroxetine $(40 \mathrm{mg} /$ day; a relapse occurred each time the patient ceased taking paroxetine, even when treated with clozapine). This course of treatment resulted in rapid and significant changes for the patient both clinically and socially; he returned home and resumed searching for a job, expressing a desire to start a family.

Table 1 presents the patient's psychometric outcomes according to daily clozapine dose.

The patient has shown no signs of relapse in the more than six months since his discharge from the hospital.

\section{DISCUSSION}

This case presents important findings consistent with the available literature regarding the effects of clozapine in nonpsychotic, self-injurious patients with BPD, showing improvement along multiple dimensions including symptom severity, impulsivity, self-mutilation, number of days of intensive observation and overall functioning.

Recent Cochrane Reviews and guidelines from the National Centre for Clinical Excellence (NICE) suggest that the various non-clozapine medications commonly prescribed for individuals with BPD have little if any therapeutic effect ${ }^{6}$; thus far, there are no clear guidelines for the use of psychotropic drugs in treating BPD.

The American Psychiatric Association practice guide- 
lines for BPD identify clozapine as a treatment that may be used when other treatments fail, ${ }^{7)}$ although only a few open studies have assessed the efficacy of clozapine in BPD patients.

In 1993, a study involving 15 BPD patients indicated that clozapine improved psychotic symptoms and overall global functioning (according to the Brief Psychiatric Rating Scale [BPRS] and scores of Global Assessment Functioning [GAF]). A subsequent study conducted in 1998 confirmed these results with 12 BPD patients treated with low-dose clozapine (25-100 mg per day). After three weeks, BPRS and GAF scores improved, as did impulsivity and mood (as measured by the Hamilton Rating Scale). ${ }^{3)}$ Other studies have demonstrated that clozapine can decrease aggressive behaviors (including self-mutilating behaviors), ameliorate relationships and decrease the frequency of hospitalization. ${ }^{8-11)}$ Dosage varies widely among studies, ranging between $25 \mathrm{mg}$ and $550 \mathrm{mg}$ per day.

These data together with our present case study support the conclusion that clozapine may be effective in BPD, particularly in cases of persistent and invasive thoughts of self-harm and suicide and for patients who exhibit severe impairment in global functioning. The appropriate dosage must be gauged relative to symptoms, but a 2013 study by Frogley et al. ${ }^{10)}$ suggests that a bloodstream level of between 360 and $430 \mathrm{ng} / \mathrm{ml}$ is needed, which was indeed the case for our patient.

Despite the lack of clear evidence, pharmacological treatment is widely used for patients with BPD. This case report corroborates previous studies supporting the use of clozapine in BPD patients who do not respond to classical pharmacological treatments, particularly those with severe suicidal thoughts or significant impairment in global functioning. Clozapine may have beneficial effects along numerous dimensions including self-harm, suicidality, interpersonal relationships, number of days spent hospitalized, and the intensity of interventions required while in hospital.
Further controlled studies are needed to establish the effective therapeutic dosage and its correlation with bloodstream level.

\section{REFERENCES}

1. Gunderson JG, Links PS. Borderline personality disorder: a clinical guide. 2nd ed. Washington, DC:American Psychiatric Pub;2008.

2. Chengappa KN, Ebeling T, Kang JS, Levine J, Parepally H. Clozapine reduces severe self-mutilation and aggression in psychotic patients with borderline personality disorder. $J$ Clin Psychiatry 1999;60:477-484.

3. Benedetti F, Sforzini L, Colombo C, Maffei C, Smeraldi E. Low-dose clozapine in acute and continuation treatment of severe borderline personality disorder. J Clin Psychiatry 1998;59:103-107.

4. Steinert T, Schmidt-Michel PO, Kaschka WP. Considerable improvement in a case of obsessive-compulsive disorder in an emotionally unstable personality disorder, borderline type under treatment with clozapine. Pharmacopsychiatry 1996;29:111-114.

5. Birchwood M. Social Functioning Scale (Markers Version) [Internet]. 2001 [cited at 2015 May 20]. Available from: http://www.researchgate.net/publictopics.PublicPostFileLoa der.html?id=550b1918d4c118466e8b45f3\&key=ae2b3e03-0 675-4cb2-8e6d-aa745c85c510.

6. Stoffers J, Völlm BA, Rücker G, Timmer A, Huband N, Lieb K. Pharmacological interventions for borderline personality disorder. Cochrane Database Syst Rev 2010;(6): CD005653.

7. Oldham J, Gabbard G, Goin M, Gunderson J, Soloff P, Spiege D, et al. Practice guideline for the treatment of patients with borderline personality disorder [Internet]. Arlington (VA): American Psychiatric Association; 2001 [cited at 2015 May 20]. Available from: http://psychiatryonline.org/pb/assets/raw/sitewide/practice_guidelines/guid elines/bpd.pdf.

8. Ferreri MM, Loze JY, Rouillon F, Limosin F. Clozapine treatment of a borderline personality disorder with severe self-mutilating behaviours. Eur Psychiatry 2004;19:177-178.

9. Zarzar T, McEvoy J. Clozapine for self-injurious behavior in individuals with borderline personality disorder. Ther Adv Psychopharmacol 2013;3:272-274.

10. Frogley C, Anagnostakis K, Mitchell S, Mason F, Taylor D, Dickens $\mathrm{G}$, et al. A case series of clozapine for borderline personality disorder. Ann Clin Psychiatry 2013;25:125-134.

11. Vohra AK. Treatment of severe borderline personality disorder with clozapine. Indian J Psychiatry 2010;52:267-269. 